\title{
Hubert De Phalese, À la recherche des Illusions perdues
}

\section{Marco Stupazzoni}

\section{Q OpenEdition}

1 Journals

\section{Edizione digitale}

URL: http://journals.openedition.org/studifrancesi/36413

DOI: 10.4000/studifrancesi.36413

ISSN: 2421-5856

\section{Editore}

Rosenberg \& Sellier

\section{Edizione cartacea}

Data di pubblicazione: 1 juillet 2005

Paginazione: 185

ISSN: 0039-2944

\section{Notizia bibliografica digitale}

Marco Stupazzoni, «Hubert De Phalese, À la recherche des Illusions perdues», Studi Francesi [Online], 145 (XLIX | I) | 2005, online dal 30 novembre 2015, consultato il 18 avril 2021. URL: http://

journals.openedition.org/studifrancesi/36413 ; DOI: https://doi.org/10.4000/studifrancesi.36413

Questo documento è stato generato automaticamente il 18 avril 2021.

\section{(c) $(1) \&$}

Studi Francesi è distribuita con Licenza Creative Commons Attribuzione - Non commerciale - Non opere derivate 4.0 Internazionale. 


\title{
Hubert De Phalese, À la recherche des Illusions perdues
}

\author{
Marco Stupazzoni
}

\section{NOTIZIA}

HUBERT DE PHALESE, À la recherche des Illusions perdues, Paris, Nizet, 2003 («Cap’Agreg», $\mathrm{n}^{\circ}$ 15), pp. 160.

1 Di dichiarata finalità didattica, come le precedenti quattordici opere pubblicate dalla collana «Cap'Agreg», questo volume si struttura in sei sezioni fondamentali: nell'introduction che inaugura le pagine del saggio, l'A. puntualizza che il lavoro critico operato sul testo balzachiano si è avvalso (in misura non sappiamo fino a che punta agevole) delle più moderne tecnologie multimediali al fine di «proposer des analyses littéraires assistées par l'ordinateur» (p. 7). Lo stesso A. dichiara di essersi «procuré le texte numérisé d'Illusions perdues sur le site de la Bibliothèque Nationale de France (programme Gallica) qui l'offre en libre accès à ses utilisateurs» (ibid.).

2 Nel primo capitolo dell'opera, vengono fornite le coordinate storico-politiche, ideologiche e letterarie entro cui si collocano l'apprendistato e la carriera romanzesca di Balzac, con particolare attenzione ai cosiddetti 'aspetti materiali' che determinarono, nella prima metà del XIX secolo, lo statuto dello scrittore narrativo. H. de Phalèse passa successivamente ad occuparsi delle particolarità e della specificità del vocabolario linguistico di Illusions perdues e, più in generale, del romanzo balzachiano colto nelle sue evoluzioni e nelle sue incertezze.

3 La terza sezione propone un'analisi mirata della poetica letteraria di Balzac attraverso lo studio del discorso paratestuale (e, in particolare, delle prefazioni) e dell'incipit romanzesco nella Comédie humaine e nell'opera considerata.

4 Il percorso tematico tracciato dall'A. su alcuni aspetti centrali di Illusions perdues (il denaro, la figura di Lucien, il contrasto Parigi/provincia, il giornalismo) forma il tessuto del quarto capitolo. Ad esso, seguono le ultime due sezioni: la quinta parte 
presenta un utile Glossaire concordance (pp. 141-151) in cui il lettore può ritrovare «pour chaque mot retenu [...] le contexte (linguistico e culturale) minimum nécessaire à la compréhension» (p. 141); la sesta sezione fornisce, infine, un sommario quadro di riferimenti bibliografici sull'opera di Balzac e su Illusions perdues, in particolare. 